\title{
The oceans: new technology for new experiments
}

\begin{abstract}
Although the oceans cover two-thirds of the Earth, they contain far more than two-thirds of the information needed to understand and model the dynamics of the global system. We must learn more about the deep ocean floor and its effects on the globe as a whole, a goal that will require new technology and international cooperation.

Previously, we thought that the ocean floor was a quiet place where processes took a long time. Now we know instead that it is a very active site of exchange between the hydrosphere, biosphere, and lithosphere and that many of the processes are of short duration. To study the deep ocean floor, we need to apply new technology in the framework of a world observatory that will provide global coverage and continuous monitoring. However, we need detailed local observations as well in order to understand the processes that we model. Space and permanent observatories both will play significant roles in our studies of the ocean, such as the study of fluid flow in accretionary wedges of subduction zones. (Ed.)
\end{abstract}

\section{Introduction}

Abundant resources of minerals and petroleum exist in the ocean areas of the world. However, in the coming decades, we are going to hear much more about the world ocean as a fundamental part of our environment, rather than as a reservoir of resources. The prevailing feeling among oceanographers today is that we first should learn more about the basic structure and operating processes of the deep ocean floor before we consider large-scale, deep-water exploitation of the natural resources.

Our environment depends on the evolution of a complex. interactive global system in which the atmosphere. hydrosphere, biosphere, and lithosphere (including the crust. mantle, and core) are linked closely. The oceans cover two-thirds of the surface of the Earth but contain far more than two-thirds of the information necessary to reconstruct the dynamics of the system. This becomes obvious when we attempt to obtain the data base necessary to validate our climatic models. Data obtainable from global arrays of holes drilled in the sedimentary layers of the oceanic crust are necessary in order to determine the responses of climate. sea level, and biological evolution to variations in the Earth's orbit and other controlling parameters.

Until a few years ago, we thought that numerous processes going on in the oceans had timeframes of thousands of years instead of the days, weeks, or years of duration that in fact they do have.
Therefore. we did not realize that continuous in-place monitoring would give us an opportunity to understand such processes. For example, on midocean ridges, volcanic and tectonic activity appear to have time constants on the order of 100 years. Gigantic underwater volcanic eruptions have occurred and are suspected to have produced drastic environmental consequences. Hydrothermal circulation. which significantly affects the ocean chemical budget, probably is modulated by the tectonic cycle, but we still know nothing about this possible modulation.

In the same way. along subduction zones, where more than 90 percent of the mechanical energy of earthquakes is dissipated at the surface of the Earth, the earthquake stress-strain cycle typically has a time constant of 100 to 150 years. The relationship of this cycle to fluid circulation within the accretionary wedge is not known, just as its relationship to the distribution and occurrence of major slumps is not known. Short-term fluctuations of fluid circulation must exist, at least at the local level, but we know nothing about them.

Previously unsuspected active erosion has been demonstrated to exist in deep ocean basins, but the active erosional processes are mostly unknown. Superhydrostatic fluid gradients have been measured in sedimentary basins where radioactive waste disposal has been considered. These findings suggest that significant fluid outflow may be present in many basins on the sea floor.

In summary, for years we considered the ocean floor to be a quiet environment that had very long time constants. We thought of the ocean crust as a dead body affected only by very slow aging. We now know that both concepts are erroneous. The sea floor is a site of much interactivity of the hydrosphere, biosphere, and lithosphere. It is affected by many short-term, poorly known processes. The oceanic crust is a living body that has active fluid circulation. which modifies it and influences the worldwide distribution of elements, such as carbon. This fluid circulation is affected by pulses reflecting the tectonic and magmatic activity of the lithosphere. And the whole oceanic system, sea floor and crust included, may be considered from the environmental point of view to be a gigantic reservoir that has complex interactions.

\section{New technology for new experiments}

Although the last two decades of the plate tectonic era have been a time of great excitement for marine geoscientists. new experiments using new technology are needed now to go beyond the remarkable discoveries that have revised completely our knowledge of the deep ocean floor. The basic concept. that seems to unify this new strategy is one of a world observatory. We need systematic real-time observations on a global scale. These observations need to be linked to a data base that will extend these observations to past geologic times in order to validate operating models. And also, we need highresolution local observations to understand the processes that we model. Real time, global. data base, models. high-resolution local observations, and processes are the key words of the new strategy that is being discussed now for the Earth. The ocean will be an important part of this effort because, as stated earlier, it contains far more than two-thirds of the information necessary to understand and model the dynamics of the global system. 
Characteristic of this new technology is the increasing alliance between space and ocean. Satellite altimetry, permitting for the first time a global vision of sea-floor morphology, has revealed unsuspected and remarkable features, such as the intraoceanic compressional deformation zone in the equatorial Indian Ocean. There, a supposedly rigid oceanic lithosphere is buckled over a width of $2,000 \mathrm{~km}$ by large-scale folds. The folding is associated with thrusting, as revealed by high-energy earthquakes. Recent drilling has demonstrated that the folding started during the late Miocene. In the next few years, new satellites will give a much denser, higher resolution coverage that will improve greatly our understanding of the tectonic history of the ocean floor.

Perhaps an even more important contribution of space to the world observatory will be the possibility of obtaining real-time data transmission from the network of sea-floor stations. Where will these stations be installed? How will they transmit their observations to the surface? What will be the respective contributions of deep-sea cables versus satellites in data transmission? We still do not know these answers, but experiments already are planned to install seismological observatories within holes that have been drilled by the Ocean Drilling Program. Thus, in December 1990, a three-component seismometer will be placed for one month within hole 504 B off Peru by the French submersible Nautile using a reentry device called Nadia. This device enables a submersible to log a previously drilled hole and to install within it, or retrieve from it, different instrument packages. Plans exist to install a more permanent station later in hole $396 \mathrm{~B}$ in the North Atlantic Ocean. The obvious aim of the seismologists, expressed at a workshop held in Woods Hole, Massachusetts, USA, in April 1988, is to establish a network of 15 to 20 sea-floor seismological observatories in order to obtain more complete global coverage.

Deep-sea data collection will not be limited to seismological observations. For little additional effort, one also could monitor on a long-term basis very important parameters such as temperatures below the sea floor, fluid pore pressure, fluid flow rate, stress, strain, and chlorinity. This would enable us to link fluid flow with deformation and to assess its relationship to earthquake cycles. We would gain some insight into the variability of the interaction between ocean and crust.

However, permanent observatories do not make sense unless their placement within the local setting has been explored carefully. To do this, the processes active there need to be studied first by using a dense, temporary network of observations. Such study requires the capability to explore and visualize the sea floor and below in detailed three dimensions. In the last few years, significant progress has been made in high-resolution sonic imagining of the sea floor by using multibeam sounders, as well as surface- and deep-towed sidescan sonar combined with deep-towed seismic-profiling systems - the prospects of development in this field are very exciting. In addition, real-time visual imaging of the ocean through deep-towed television, together with the possibility of sophisticated sampling and other operations by robots and submersibles on the sea floor, has changed the nature of deep-sea exploration.

As discussed in the Second Conference on Scientific Ocean Drilling in Strasbourg, France, in July 1987, permanent observatories would need repeated visits to given sites (JOIDES, 1987). These visits would require the capacity to reenter deep drill holes for logging, maintenance, and data retrieval; to conduct high-resolution exploration as described above; and, finally, the possibility to core dense networks of shallow drill holes (fig. 1). The scientific community still has to provide adequate surface platforms from which such tasks might be performed, and costs must be reasonable. Projects do exist now, and their implementations are being discussed in the framework of the future international drilling program beyond the year 1992.
Figure 1.-Drawing of proposed light station ship called NEREIS. Such a ship could be outfitted with equipment to conduct high-resolution sea-floor exploration, to reenter previously drilled deep holes for servicing permanently installed stations or doing logging, and to core shallow (300-m-deep) drill holes. This project is now being discussed in Europe.

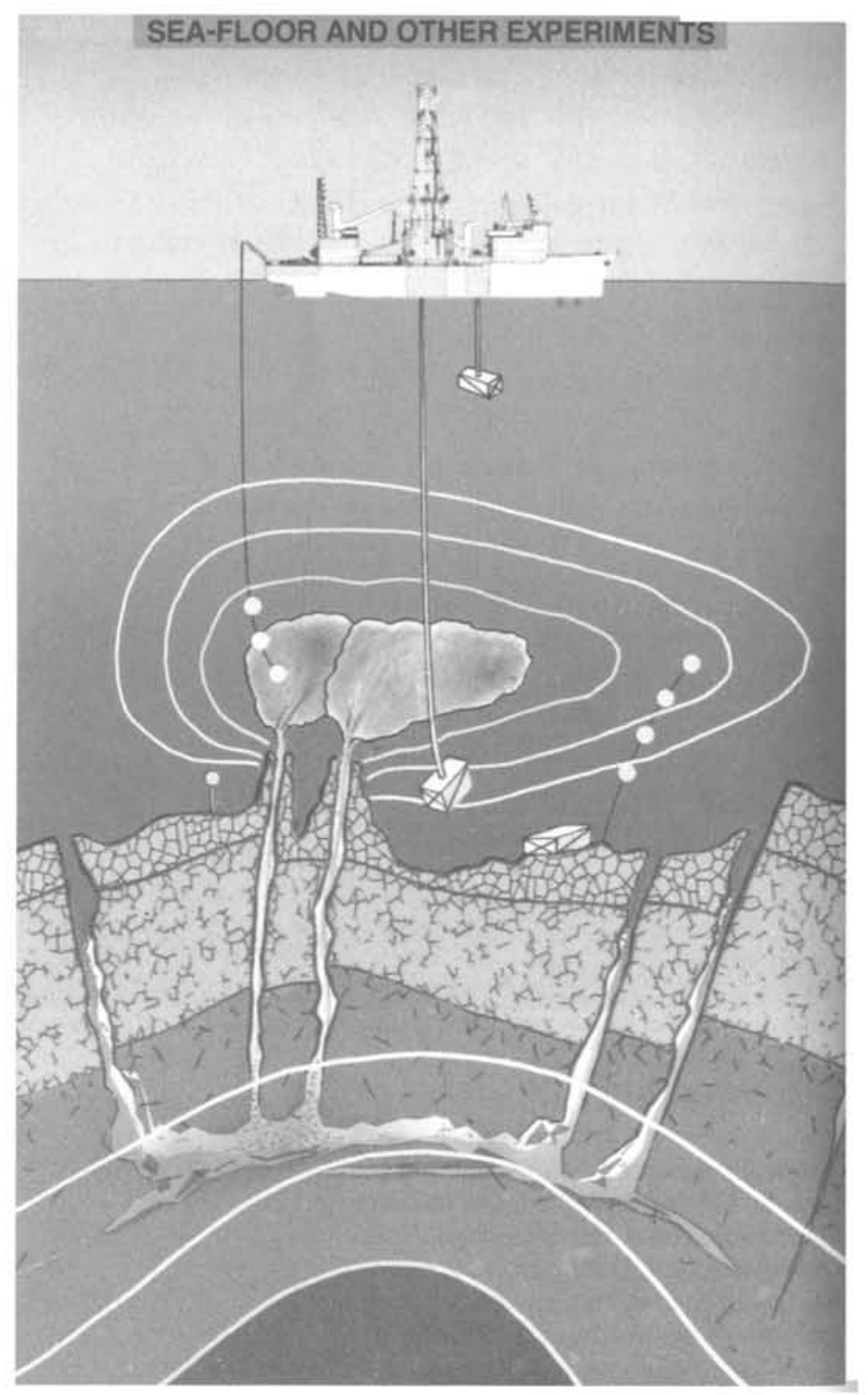

\section{An example of deep-sea observatories: fluid flow in accretionary wedges of subduction zones}

To illustrate the kind of science that we could expect from deep-sea observatories, I will describe briefly the problem of fluid flow in accretionary wedges of subduction zones, as it was discussed in a NATO/NSF workshop in Il Ciocco, Italy, in September 1988 (Lang seth and Moore, in press).

Subduction zones are the most dynamic environment on the Earth. The earthquakes of trenches contribute more than 90 percent of the world's release of seismic energy, and most of the world's largest earthquakes, such as the 1960 Chilean earthquake, have originated in these regions. Yet, although the epicentral region is subma 


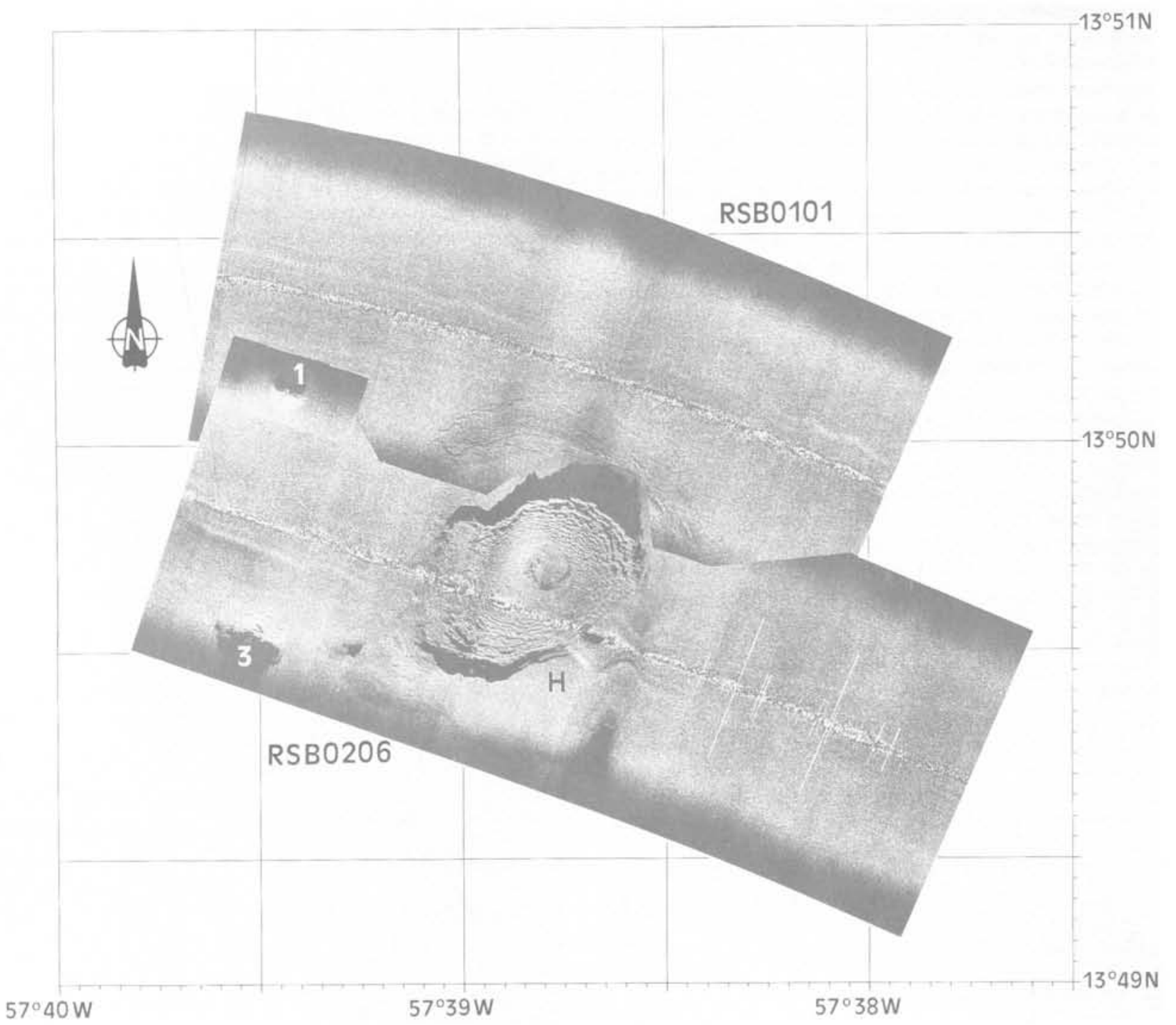

Figure 2. - Deep-towed side-looking sonar image of a mud volcano $(H)$ and two small diapirs $(1$ and 3 ) in an active mudvolcano field at a 5,000-m water depth in the Barbados frontal wedge. $H$ is actually a gigantic mud pie about $1,000 \mathrm{~m}$ by $600 \mathrm{~m}$. Notice the central eye where active mudflows still occur. This mud pie is actively venting huge quantities of highpressure fluids that have a high thermogenic methane content and come from the décollement level below the accretionary wedge (taken from Henry and others, in press).

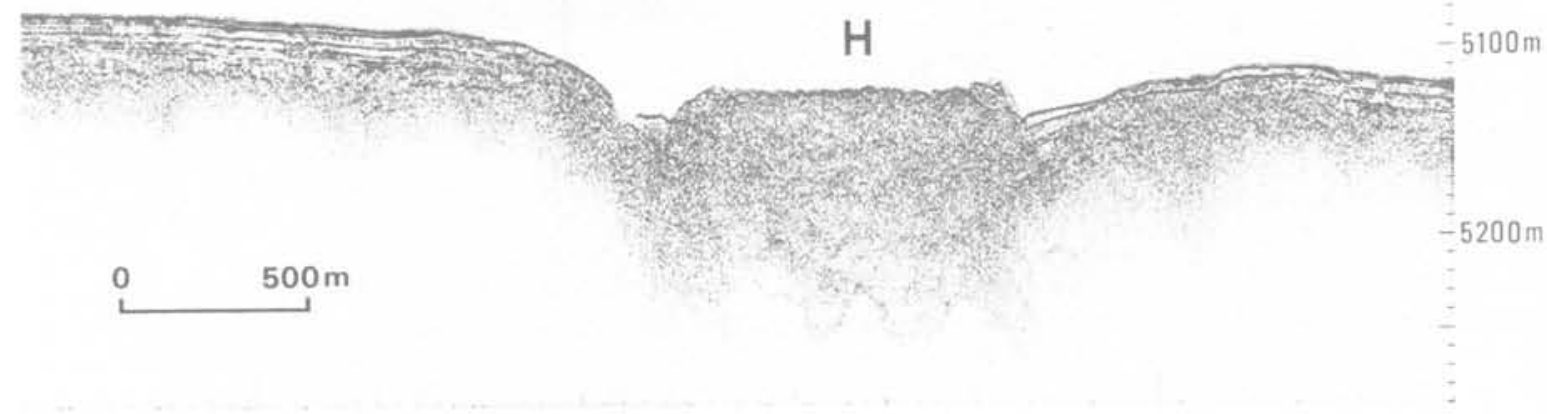

Figure 3.-Deep-towed mud-penetrator profile on mud pie $\mathrm{H}$ of figure 2. The mud pie is about $50 \mathrm{~m}$ thick and sits on top of the rapidly subsiding sea floor. It has been active for about 30,000 years. 
rine, we have little direct information on the pattern of cyclic deformation there. Very few permanent underwater observatories monitor this deformation today.

A significant feature of many subduction zones is the presence of a large accretionary wedge that is formed by sediments scraped from the subducting lithosphere. These wedges grow through stacking of high-porosity sediments; consequently, one expects that their tectonic, thermal, and chemical evolution would be influenced strongly by fluids. Theoretical modeling further has shown that the fluid pressure in the wedge should be close to lithostatic pressure, especially within the décollement, which enables the oceanic lithosphere to glide below the wedge with a minimum amount of friction. In a sense, the wedge can be considered to be a well-lubricated shock absorber between the seismic high-friction subduction plate further inland and the deep-sea trench.

High superhydrostatic pore pressures obviously suggest that porewater migration within the wedge, as well as flow out of the wedge, should be expected. Indeed, the Ocean Drilling Program has found evidence for large-scale flow not only along the décollement off the north coast of South America but also along active thrusts in the Barbados frontal wedge. A high-resolution, precisely navigated sonar and seismic-reflection survey (deep-towed combined with side scan) revealed the detailed three-dimensional structure. This survey, complemented by pogo-meter heat-flow measurements spaced $100 \mathrm{~m}$ apart, showed that surface outflow is localized along narrow regions of tight back thrusting. On the basis of the surface-heat anomaly, the outflow estimate is too large to be explained by steady-state dewatering of the sedimentary column. Instead, it requires large-scale lateral transport and (or) transient flow.

A mud-volcano field on the seaward side of the same Barbados frontal wedge was discovered and explored by using first the same deep-towed system and then a deep-diving submersible (figs. 2, 3). Heat-flow measurements and sampling from the submersible at spacings of meters to tens of meters demonstrated very large amounts of fluid outflow through the mud volcanoes and diapirs. The fluid outflow seems to tap the high-fluid-pressure layer produced by seaward propagation of the high-pressure zone along the décollement. This evidence again suggests that steady-state dewatering of the sediments entering the wedge is not able to account for the flow observed. Therefore, we should look for other sources of fluid.

The questions then are whether these additional sources of fluid are related to the earthquake stress cycle and, if so, whether the observed flow of fluid out of the wedge is modulated by this stress cycle. How could one test this hypothesis? Submersible surveys off Oregon, USA, and Japan have shown that fluid vents are the sites of dense colonies of clams (Calyptogena) and thus could be identified easily. The outflow velocity is sufficiently fast (about $50 \mathrm{~m}$ per year) to give a characteristic profile of the advective subbottom temperature. Therefore, because the density of the colonies could be related to the velocity of outflow, a relatively simple visual survey could produce a quantitative estimate of the outflow. In addition, ongoing measurements of the surface-temperature profile over a few selected colonies could provide a relatively simple way to monitor the variation of the flow of fluid with time. If this set of measurements was combined with information from drill holes containing recording instruments, then a three-dimensional monitoring of the flow of fluid in and out of the accretionary wedge would be possible.

\section{Conclusion}

I could have used several other examples of problems that require this new approach to studying the oceans, characterized by global coverage and continuous monitoring, as well as detailed local investigations, in order to analyze well-identified processes. The required technology exists or can be developed easily. However, the technology is expensive and requires international cooperation. Such cooperation can be extremely successful, as demonstrated by the two decades of scientific ocean drilling, provided the scientific goals are reassessed continuously and the necessary new technology is developed. In this "Planet Earth" decade that we are entering, let us remember that the unique character of the Earth is related to its ocean and that no program to study the dynamic evolution of the Earth's surface is likely to succeed unless it takes fully into account the role played by the ocean.

\section{References}

JOIDES (Joint Oceanographic Institutions for Deep Earth Sampling), 1987, Conference on Scientific Ocean Drilling (Cosod II), 2nd, Strasbourg, France, 1987, Report: Strasbourg, European Science Foundation, 142 p. Langseth, M.G., and Moore, J.C., in press. Fluids and accretionary prisms: Report on a NATO/NSF sponsored workshop: EOS (American Geophysical Union Transactions).

Henry, Pierre, Le Pihcon, Xavier, Lallemant, Siegfried, Foucher, J.-P., Westbrook, Graham, and Hobart, Michael, in press, Mud volcano field seaward of the Barbados accretionary complex: A deep-towed side scan sonar survey: Journal of Geophysical Research.

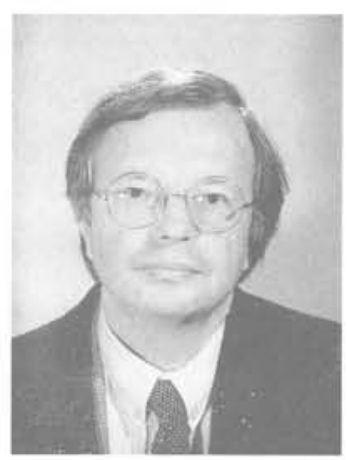

Dr. Xavier Le Pichon, born in 1937, is a geophysicist and an oceanographer. He is presently Titular of the Chair of Geodynamics at the College de France in Paris, as well as Director of the Department of Geology at the Ecole Normale Superieure there. In the last few years, he has been involved more particularly in a research program investigating the role of fluids in subduction zones, and he has coorganized several submersible research cruises off Japan (Kaiko program) and off Barbados. 